WIENER SLAVISTISCHES JAHRBUCH, Band 57/2011, 151-158

(C) 2011 by Österreichische Akademie der Wissenschaften, Wien

GERHARD NEWEKLOWSKY

\title{
László Hadrovics kao istraživač jezika i kulture Gradišćanskih Hrvata ${ }^{1}$
}

Kao što je poznato, usljed prodiranja osmanskih osvajača na Balkanski poluotok u 16. stoljeću naseljeni su Hrvati u velikom broju iz ugrožene domovine u zapadnu Ugarsku i Donju Austriju. Na osnovu povijesnih i dijalekatskih podataka možemo zaključiti da kao njihova prvobitna postojbina dolazi u obzir područje između rijeka Save, Une i Kupe, zatim zapadna Slavonija kao i bosanska strana doline Une (v. Neweklowsky 1978: 264-281). U Donjoj Austriji postojao je veliki broj hrvatskih naseobina u Marchfeldu i drugim mjestima sjeverno od Dunava, zatim između Dunava i Lajte na jugu. U Ugarskoj su Hrvati naseljeni u županijama Požonj (Bratislava/ Pressburg), Sopron (Ödenburg), Moson (Wieselburg), Vass (Eisenburg). Godine 1921. veći dio ovog područja - s izuzetkom grada Šoprona i županije Požonj - plebiscitom je pripojen Austriji; od triju mađarskih županija načinjena je austrijska pokrajina Burgenland (naziv prema njemačkim imenima na -burg). Hrvatski naziv „Gradišće“ je kalkiran prema njemačkom terminu. Jedan manji dio hrvatskih naselja ostao je u Mađarskoj, nekoliko sela u Slovačkoj, a do 1948. godine postojala su tri hrvatska sela u južnoj Moravskoj, kad je njihovo stanovništvo iseljeno pod komunističkom vladom Čehoslovačke (up. karte u: Brabec 1966 i Breu 1970).

Ova hrvatska narodna skupina je krajnje zanimljiva: Hrvati govore jedan starinski jezik koji se prenosi od 16. stoljeća iz jedne generacije u drugu i kojeg danas u Hrvatskoj nema. Oni imaju svoj vlastiti književni jezik koji se razvijao neprestano od početka 17. stoljeća. Hrvatski jezik ovdje živi u zanimljivim jezičnim kontaktnim situacijama, s njemačkim, mađarskim, slovačkim, nekada i sa češkim jezikom. Za jezičnu situaciju u prošlosti ne treba zanemariti utjecaj latinskog jezika, jer su pisci svećenici - bili školovani na latinskom jeziku. Danas hrvatski standardni jezik vrši

${ }^{1}$ Predavanje na simpoziju „Emlékulés Hadrovics László születésenek 100. évfordulóján“ (Proslava stogodišnjice rođendana Lászla Hadrovicsa) 15. lipnja 2010. u Budimpešti. 
veliki utjecaj na hrvatski književni jezik Gradišća. Kod Gradišćanskih Hrvata postoji bogata folklorna tradicija, usmena književnost, postoji religiozna književnost od samog početka, a svjetovna od 19. stoljeća. Danas ovi Hrvati imaju i svoje rječnike, svoju gramatiku, svoj pravopis.

Narodna skupina Gradišćanskih Hrvata izazvala je zanimanje akademika profesora Lászla Hadrovicsa, i to iz više vidika: Na području zemalja ugarske krune razvijalo se nekoliko regionalnih književnih jezika koji odstupaju od književnih jezika dotičnih matičnih zemalja, drugo - jedno od omiljenih znanstvenih područja L. Hadrovicsa bila je leksikologija i etimologija. To je široko polje istraživanja leksičkih posuđenica, tuđica mađarskog, njemačkog, romanskog i drugog porijekla, područje koje je Hadrovics promatrao s kulturološkog vidika prateći puteve pozajmljivanja riječi lektirom izvornih tekstova. A treći podsticaj je bila, prema mom mišljenju, sintaksa. Kao što znamo, Hadrovics se bavio temljito i mađarskom funkcionalnom sintaksom.

Hadrovics je autor opširne monografije (564 str.) o književnoj djelatnosti i jeziku Gradišćanskih Hrvata u 18. i 19. stoljeću (Hadrovics 1974). Međutim, nacrt za ovakvo djelo nije nastao preko noći. U knjizi nalazimo podatak da se Hadrovics za nju odlučio već 1951. (str. 13), što znači da je radio na njoj više od dvadeset godina. On je pripadao onoj generaciji znanstvenika koji nisu bili prisiljeni da objavljuju neprestano, nego je radio decenijama na jednoj temi, a kad je sinteza bila gotova, objavio je veliko djelo. Slično je Hadrovics postupao kad je pisao mađarsku sintaksu. ${ }^{2}$

Sjećam se kako je Hadrovics godine 1966. dolazio u Beč i posjetio bečku slavistiku. Budući da prije toga nije mnogo objavljivao o jeziku Gradišćanskih Hrvata, znali su samo oni o njegovim planovima kojima je to i ispričao. Savjetovao se je s pročelnikom bečke slavistike, Josipom Hammom. Ja sam se baš tada intenzivno bavio dijalektološkim istraživanjima kod Gradišćanskih Hrvata i završio svoju disertaciju o naglasku u čakavskim govorima (Neweklowsky 1966), tako da mi je zaista bila čast razgovarati i savjetovati se s profesorom Hadrovicsem. Odveo sam ga u Phonogrammarchiv Austrijske akademije znanosti koji je bio smješten u istoj zgradi kao i slavistika, u Liebiggasse 5, nedaleko glavne zgrade Bečkog sveučilišta, gdje smo preslušavali dragocjene magnetofonske snimke snimljene u pedesetim godinama od strane austrijskih germanista koji su radili na dokumentaciji austrijskih govora, njemačkih ali i drugih. Ovi se snimci i danas mogu upotrijebiti. U daljim razgovorima je profesor Hadrovics obećao da bi nam - preko Mađarske akademije znano-

2 „Während seiner wissenschaftlichen Laufbahn bereitete László Hadrovics bisher ohne Zweifel dadurch die größte Überraschung, dass er, nach einer slawistischen Tätigkeit von drei Jahrzehnten, für einige Jahre auf das Gebiet der ungarischen Satzlehre überging und, ohne früher auch nur einen einzigen Artikel über syntaktische Fragen zu publizieren, auf einmal mit einem ganzen Buch auftrat und dazu mit einem Werk, das die Grundlagen einer ganz neuen, vom Autor als funktionell benannten ungarischen Satzlehre niederlegte und das - nach der Intention des Autors - die Auffassung über die ungarische Syntax revolutionieren muss“" (Kiss 1970: 185). 
sti - organizirao ekspediciju u hrvatska sela gradišćanskog tipa u Mađarskoj. To nije bilo sasvim lako, jer se za vrijeme željezne zavjese nije moglo slobodno putovati u pograničnom pojasu, i to u sumnjive svrhe bilježenja jezika hrvatske manjine. Hadrovics je zaista uspio organizirati ekspediciju. U proljeće 1967. profesor Hamm i ja putovali smo kolima u Budimpeštu, gdje nas je primio Hadrovics. Bili smo kod njega i njegove supruge u gostima, a sutradan smo otputovali s docentom Lászlom Dezső-em u pogranični pojas prema Austriji, gdje žive Hrvati. Nas trojica smo obilazili u Mađarskoj ova hrvatska naselja: Vedešin (Hidegség), Umok (Fertőhomok), Undu (Und), Prisiku (Peresznye), Hrvatski Židanj (Horvátzsidány), Temerje (Tömörd), Nardu (Nárda), Čatar (Csatár), i Hrvatske Šice (Horvátlövő). Dijalektološke podatke koje smo tada zapisali, uvrstio sam u svoju monografiju o hrvatskim govorima Gradišća, tekstovi iz spomenutih sela osim Hrvatskih Šica objavljeni su u njoj (Neweklowsky 1978). Bolji magnetofonski snimci arhivirani su u Phonogrammarchivu (up. Online-katalog http://catalog.pha.oeaw.ac.at/ui/index.php). Postojanje hrvatskih snimaka se spominje u članku Hadrovics 1973, str. 25.

Prije izlaska značajne Hadrovicseve knjige 1974. nije se općenito znalo da je Hadrovics bio najbolji poznavalac književnog jezika Gradišćanskih Hrvata, jer osim jednog, iako dosta opširnog, članka iz 1958. godine za Kongres slavista u Moskvi - do tada iz te oblasti nije ništa objavio. Spomenuti se članak zove „Adverbien als Verbalpräfixe in der Schriftsprache der burgenländischen Kroaten“ (Hadrovics 1958). Hadrovics smatra da je pojava upotrebe karakterističnih priloga u funkciji glagolskih prefiksa uvjetovan njemačkim i mađarskim utjecajem na hrvatski jezik. U monografiji (Hadrovics 1974) ima također jedno poglavlje o ovoj tematici, ali je kratko (5 stranica) prema skoro $40 \mathrm{u}$ navedenom članku. Radi se o tipu muke van stati prema njem. „Qualen ausstehen“" i mađ. „kínokat kiállni“, ili grad nuter zeti „eine Burg einnehmen“, „várat bevenni“, i slično (Hadrovics 1974: 183). Ovakve se konstrukcije javljaju u hrvatskoj pismenosti zapadne Ugarske od samog početka. Godine 1973., tj. skoro istovremeno s knjigom, izašao je članak o sintaktičkim novotarijama u književnom jeziku Gradišćanskih Hrvata (Hadrovics 1973b).

Velika Hadrovicseva zasluga se sastoji u tome što je inventarizirao književnu djelatnost zapadnougarskih Hrvata i što je sakupio knjige 18. i 19. stoljeća. Imao sam priliku da vidim zbirku u njegovom kabinetu u Slavističkom institutu budimpeštanskog sveučilišta. Hadrovics je sudjelovao u simpoziju „Mogersdorf“ 1970. godine, te je tamo podnio izvještaj o svom radu na književnom jeziku Gradišćanskih Hrvata. U tom članku (1973a) i u knjizi (1974) nalazimo podatke o ovoj književnosti koja je u osnovi religiozna. Hadrovics navodi najstarije zapise i tekstove, naime latiničke, ćiriličke i glagoljske zapise u Klimpuškom misalu 1564. godine (1974: 20 sl.), zatim Postilu 1568., posljednju knjigu hrvatskih protestanata ${ }^{3}$, zatim Duševne pesne

${ }^{3}$ Karakteristično je za Hadrovicsevu akribiju i način rada da bilježi kako je našao jedan primjerak Postile u Sveučilišnoj biblioteci u Budimpešti (1973a: 26), ili piše kako je našao 
Grgura Pythiraeusa-Mekinića 1609. i 1611. ${ }^{4}$, pa Sudski zapisnik (Gerichtsprotokoll) u rukopisu iz g. 1625., te Hrvatsko evanđelje 1732. i Lekcionar Ladislava Valentića 1741., Hrvatski slabikar (koji nije sačuvan), Katekizam itd. Jezik Mekinićevih pjesmarica kao i sudski zapisnik odudaraju jezično od ostalih književnih djela, u kojima se književni jezik stabilizira. Te posebnosti jezika pjesmarica i sudskog zapisnika (u kojima ima također slovenskih elemenata) treba tek proučiti i tumačiti. U Hadrovicsevoj knjizi objavljeni su izvaci tekstova između 1609. i 1864. (1974: 495-539). Ovi su primjeri dragocjeni jer je ta književnost vrlo teško dostupna.

Živi hrvatski govori Gradišća i susjednih područja nisu jedinstveni; nalazimo čakavske ikavsko-ekavske, čakavske ikavske, prelazne čakavsko-štokavske i kajkavske govore. Oni se međusobno dosta razlikuju, naročito u fonetici. Ipak imaju vrlo mnogo zajedničkog, naročito u leksiku, gdje nalazimo mnogo podudaranja s kajkavskim narječjem, a manje sa čakavskim govorima Dalmacije, što govori u prilog njihova porijekla s unutrašnjosti, a ne s obale. Dijalekatska su osnova gradišćanskohrvatskog književnog jezika čakavski ikavsko-ekavski govori sjevernog i srednjeg Gradišća. Hadrovics opisuje njihov književni jezik. Kaže da je njihov fonetski i pravopisni sustav dosta jednostavan. Hrvatski pravopis prema kajkavskoj i mađarskoj tradiciji, tj. bez konsekventnog razlikovanja $\check{c}$ i $c$, počinje sa pjesmaricama 1609. i 1611., dok čakavski pravopisni sustav (opet na mađarskoj osnovi) sa razlikovanjem svih nužnih fonema počinje s Evanđeljem 1732. (Hadrovics 1974: 49). Vokalni sustav se sastoji iz pet vokala plus slogotvornog $r$. U govorima postoje također diftonzi, koji se u književnom jeziku dakako ne pišu. Hadrovics upozorava na upotrebu akuta prema mađarskom uzoru, najčešće ga ima na vokalima é i $o$, i, zaista, kad uporedimo primjere s oblicima u živim govorima, jasno je da se tu radi o diftonzima tipa [ie] u piet (pét) i [uo] u buog (bóg). Jedna osobina književnog jezika je činjenica da se naglasak ne bilježi. Iz dijalektologije pak znamo da se tu radi o jezičnom sustavu s parcijalnim pomicanjem mjesta akcenta.

Jedno od najvažnijih obilježja književnog jezika Gradišćanskih Hrvata je refleks jata kao $i$ i $e$ (ikavsko-ekavski). Hadrovics kaže da je refleks jata obično $i$, a u ograničenom broju primjera $e$. Zakon Jakubinskoga ima veliki broj izuzetaka, zato navodi popis riječi sa $i$, i popis riječi sa $e$, npr.: a) bižati, brig, brime, človik, črivo, dite ..., b) bel, bled, cena, cesta, cvet, ded, len, mesto, pesak, ... (1974: 54-59). Zanimljivo je da u tiskanim izvorima nema miješanja. Pretpostavljam da među piscima nije bilo ikavaca iz južnog Gradišća. Zatim Hadrovics opisuje cijeli fonetski razvoj

primjerak Hrvatskog evanđelja 1732. u mađarskoj Nacionalnoj biblioteci 1971., koji je do tada bio sasvim nepoznat (Hadrovics 1973a: nap. 2). Pošto je Hadrovics i ovu knjigu tek otkrio kad je njegova knjiga bila uglavnom gotova, mogao je ugraditi u nju samo osnovne gramatičke osobine Evan đelja, dok je u poglavlje o leksiku ušlo više (Hadrovics 1974: 45). O jeziku Evan đelja 1732. pisao je István Nyomárkay (Nyomárkay 1973).

4 Ove dvije knjižice tek su pronađene 1969., kad je gramatički opis knjige već bio gotov, tako da su samo djelomično iskorišćene za monografiju. 
gradišćanskohrvatskog književnog jezika, tvorbu riječi i morfologiju. Podaci nam dokazuju opet da je ovaj književni jezik jednoznačno čakavski. Uostalom, prva znanstvena gramatika gradišćanskohrvatskog književnog jezika (Sučić 2003) pokazuje, kako se ona i danas temelji na tradiciji koja je počela s Hrvatskim evanđeljem 1732. Znanstvena gramatika potvrđuje Hadrovicsev opis. Razlika je u tome što $u$ književnom jeziku 18. i 19. stoljeća nema utjecaja hrvatskog standardnog jezika, što je danas slučaj.

Morfologija imenica odgovara stanju u čakavskim i kajkavskim govorima. U lok. jedn. muškog roda nalazimo $-u$ pored $-i$ (npr. va paradižomu/paradižomi, na ne$b u / n e b i)$. U instr. imenica na $-a$ upotrebljava se najčešće nastavak -um (zi ženum) kao u kajkavskom jeziku 17. i 18. stoljeća, dok se u govorima upotrebljavaju -u i -om (u današnjem književnom jeziku samo posljednje). Kod glagola aorist i imperfekt se upotrebljavaju samo u Evanđelju 1732., kasnije više ne. Nastavak 3. lica množine glasi najčešće na -u, npr. skažu, kažeju, vežeju, govoriju, moliju, rijedak je tip govore.

Kod pridjeva Hadrovics nije mogao uočiti da se određeni i neodređeni pridjevi dobro razlikuju, jer se tu koriste najčešće prozodijska sredstva. On ipak konstatira da gen. jedn. ženskog roda kao i gen. jedn. muškog i srednjeg roda češće nose akcenatski znak, npr. tešké, žuké, zubné, svitlóga. Iz Gramatike (Sučić 2003: 126 sl.) vidi se da dužine (u živom jeziku diftonzi) dolaze samo u neodređenom vidu.

Kod zamjenica treba istaći da se oblici njega i nje upotrebljavaju i u funkciji prisvojnih zamjenica „njegov“ i ,njen“, akuz. jedn. srednjeg roda je sačuvao stari oblik nje, je (str. 210).

Hadrovics obrađuje i leksik. Njegov glosar (440-493) obuhvaća naravno samo mali dio leksičkog blaga, za njega zanimljivije riječi na otpr. 50 stranica s etimološkim objašnjenjima. Kad se, međutim, vodi računa i o indeksu riječi (u kojem ima blizu 3.000 natuknica) može se predočiti donekle leksičko bogatstvo. U njemu ima, kako se može i očekivati, latinskih, romanskih, mađarskih i njemačkih elemenata. Navodimo nekoliko primjera: advokatuš (iz latinskog, -š ukazuje na mađarski izgovor latinskih riječi), akar-ki ,bilo tko“ (neodređena zamjenica, pozajmljenica iz mađarskog akarni „,htjeti, željeti“), aldovati „žrtvovati““ (iz mađ. áldozni), batriti „,tješiti“ (mađ. bátoritani), bermati „krizmati“ (iz njem. firmen), beteg „bolest“ (iz mađ. beteg „bolestan“), betežan „bolestan“, betežnik „bolesnik“, bohta „straža“ (iz njem. Wächter), canjak „krpa“, cimitor ,groblje“ (iz romanskog, tal. cimitero), deak „literatus, Schreiber“, deački, dijački, jački „latinski“" (ovamo pripadaju i jačiti „pjevati“, jačka „,pjesma“), dugovanje „stvar“, durati „trajati“ (lat., tal. durare), falinga „pogreška“ (iz njem.), itd., itd. Tipični leksik južnog Gradišća nije zastupljen, npr. u pismenosti nalazimo kucak ,pas“ (ne cucak), čemeran „loš“ (ne poredan), hržulja „raž“ (ne hrž), lug (ne pepel), pladanj (ne tanjir), veža (ne kuhnja), protuliće (ne premaliće), pandiljak (ne prvi dan), peteh (ne pivac) itd.

Zanimljivo je i kalkiranje prema njemačkim i, rjeđe, mađarskim uzorima: dati se prema njem. „sich begeben“ (kada se na počivak damo „,wenn wir uns zur Ruhe be- 
geben“), podstati se prema „sich unterstehen“ (dalje se ov paklenski napastnik podstoji siromaškoga betežnika na smrtnoj postelji va samoj veri skušavati ,weiters untersteht sich dieser höllische Versucher, den armen Kranken auf dem Totenbett im Glauben selbst zu versuchen“), zatim nominalizacija tipa posluh dati „Gehör schenken“, norije goniti „Unsinn treiben“, konac zeti „,ein Ende nehmen“, dalje frazeologizme kao: na klinac obisiti ,an den Nagel hängen“, gornju ruku pustiti „die Oberhand gewinnen (lassen)“, kraće potegnuti „den Kürzeren ziehen“ i dr. (1974: 435440). Ovakvi primjeri dokazuju kakav je veliki utjecaj imao njemački jezik na hrvatski.

Hadrovicseva ljubav prema sintaksi vidi se i u njegovoj knjizi, gdje ona ima opširan prostor (str. 264-429). Iako je već tada objavio knjigu o sintaksi mađarskog jezika, kaže da je ipak ostao kod tradicionalnog opisa, jer nema uopće uzora za povijesnu sintaksu hrvatskog (i srpskog) jezika (1974: 264). U analitičkom dijelu opisuje (morfo)sintaksu vrsta i oblika riječi, npr. rod, broj i deklinacioni tip pojedinih leksema (npr. vazam „uskrs“ se upotrebljava kao nom. jednine, ali se u kosim padežima upotrebljavaju oblici množine: od vazam do duhov, $k$ vazmom). Kod zamjenica sebe i svoj (277 sl.) vidimo da već u 18. stoljeću ima dosta izuzetaka pravilne slavenske upotrebe, naročito kod moj i tvoj, npr. prosim od njega meni $i$ mojim potribne milošće, što je očigledno strani utjecaj. Zatim, opisuje sintaksu imeničkih oblika riječi (str. 286 i dalje), to jest, upotrebu pojedinih padeža u raznim funkcijama. Između ostalog opisuje upotrebu akuzativa i lokativa za mjesto ili pravac radnje bez prijedloga, npr. Bog se j rodil Bethlehemi, umjesto va Bethlehemi, već u najstarijim tekstovima. Meni se čini da je to utjecaj njemačkog razgovornog jezika, u kom se govori npr. ich fahre Wien, ich war Wien (umjesto nach/in Wien). Dalje, govori se o upotrebi prijedloga (312-362), o sintaksi glagolskih oblika (362-381). Sintaksa rečenice obrađuje sve vrste rečenica, jednostavne rečenice kao i sve vrste složenih rečenica. Ovo treba istaći posebno, jer se povijesna sintaksa obrađuje rijetko.

Treba reći da je Hadrovicsev doprinos o jeziku pismenosti Gradišćanskih Hrvata u 18. i 19. stoljeću veoma značajan; bez njegova rada znali bismo veoma malo o jeziku te pismenosti i književnosti. Dokazuje se da je kontinuitet književnog jezika Gradišćanskih Hrvata od 18. stoljeća sve do danas neprekidan. Suvremena znanstvena gramatika (Sučić 2003) je dokaz za to. Danas se gradišćanskohrvatski jezik obogaćuje suvremenim hrvatskim standardnim jezikom, ali se to ipak ograničava uglavnom na leksik i terminologiju, a ne na sistem gramatike.

Hadrovics je objavio 1995. godine dosta opširan članak na hrvatskom jeziku u okviru projekta „Povijest i kultura Gradišćanskih Hrvata“. Taj je članak samo djelomično sažetak knjige 1974. Budući da sam ja također sudjelovao u ovom projektu zna se da je članak bio prvo napisan na njemačkom jeziku za njemačko izdanje (do koje do sada nije došlo) i da je rukopis predan 1980. godine ili nešto ranije. U navedenom članku Hadrovics popunjava naše znanje o izvorima (uglavnom neštampanim), opisuje pravopisne, fonetske i morfološke posebnosti njihova jezika te se bavi sociolingvističkom povijesti jezika u 19. i 20. stoljeću. 
Poslije velike knjige i gore navedenog članka je Hadrovics - koliko mi je poznato - objavio samo jedan članak koji je povezan s Gradišćanskim Hrvatima, naime „Burgenländisch-kroatische Schulbücher der Bachära“ (1984.). Radi se o razdoblju između 1850. i 1860. g. Školske knjige onog doba jedva su poznate i, ako uopće, sačuvane u samo nekoliko primjeraka. Hadrovics opisuje vanjsku povijest nastanka tih školskih knjiga služeći se raznim arhivima, dok nije imao priliku opisati i njihov jezik. Kad su nastale školske knjige u Hrvatskoj i Slavoniji u pedesetim godinama 19. stoljeća, postavilo se je pitanje da li se one mogu upotrijebiti i u Ugarskoj. Samo u đurskoj biskupiji digao se otpor, jer se tadašnji književni hrvatski jezik previše razlikovao od hrvatskog jezika tamošnjeg stanovništva. Osobe koje su se bavile prerađivanjem udžbenika bili su kulturni radnici kao Fabian Hauszer i Gašpar Glavanić. Oni su htjeli približavati gradišćanskohrvatski jezik hrvatskom književnom jeziku, također pravopisu ilirizma, ali njihovi uspjesi nisu bili trajni, nego su se Hrvati vratili opet starom mađarskom pravopisu i lokalnom dijalektu.

Poslije navedenog članka (1984.) čini se da se Hadrovics više nije obraćao jeziku i kulturi Gradišćanskih Hrvata, bar ne u pismenom obliku.

Akademik Hadrovics je sa svojom velikom monografijom i manjim brojem članaka o jeziku Gradišćanskih Hrvata stekao ugled najboljeg poznavaoca tog regionalnog književnog jezika. On je položio temelj za njegov opširni gramatički opis. Kad se čitaju Hadrovicsevi radovi, osjeća se kako je svaki njegov rad prožet temeljitim znanjem izvora i akribijom dokumentacije. Osjeća se njegovo poznavanje kulturne i opće povijesti kad piše o pozajmljivanju riječi, o tvorbi kalkova, o sintaksičkim konstrukcijama, o pismenosti i književnosti, o udžbenicima i drugim. Osjeća se također da je cijela njegova djelatnost motivirana nastojanjem oko tumačenja mađarsko-južnoslavenskih odnosa. Kod Hadrovicsa gramatički opis nije jedini cilj, nego je filološki rad koji uzima u obzir jezične kontakte koji mogu objasniti građu.

\section{Literatura}

Bibliografija Hadrovicsevih radova objavljena je u: Studia slavica hungarica 16 (1970) 187-192, 25 (1979) 11-13, 36 (1990) 13-15

Hadrovics 1958: $\quad$ László Hadrovics, Adverbien als Verbalpräfixe in der Schriftsprache der burgenländischen Kroaten, Studia slavica hungarica 4, 211-249

Hadrovics 1973a: $\quad$ László Hadrovics, Schrifttum und Sprache der Burgenländischen Kroaten im 18. und 19. Jahrhundert, u: Amt der Burgenländischen Landesregierung, Landesarchiv (Hrsg.), Internationales Kulturhistorisches Symposium Mogersdorf 1970 in Mogersdorf „Österreich und die Südslawen“, Eisenstadt, 25-32

Hadrovics 1973b: $\quad$ László Hadrovics, Syntaktische Neuerungen in der Schriftsprache der burgenländischen Kroaten, Studia slavica hungarica 19, 59-74

Hadrovics 1974: $\quad$ László Hadrovics, Schrifttum und Sprache der Burgenländischen Kroaten im 18. und 19. Jahrhundert, Budapest und Wien

Hadrovics 1984: $\quad$ László Hadrovics, Burgenländisch-kroatische Schulbücher der Bachära, u: Burgenländisches Landesarchiv (Hrsg.), Burgenland in seiner 
pannonischen Umwelt. Festgabe für August Ernst (= Burgenländische Forschungen, Sonderband VII), Eisenstadt, 140-150

Hadrovics 1995: $\quad$ László Hadrovics, Povijest gradišćanskohrvatskoga književnog jezika, u: Ivan Kampuš (glavni urednik), Povijest i kultura Gradišćanskih Hrvata, Zagreb, 465-485

Kiss 1970: $\quad$ Lajos Kiss, László Hadrovics sechzigjährig, Studia slavica hungarica $16,179-186$

Neweklowsky 1966: Gerhard Neweklowsky, Die Akzent- und Intonationssysteme der čakavischen Mundarten des Burgenlandes, Wien (disertacija u rukopisu)

Neweklowsky 1978: Gerhard Neweklowsky, Die kroatischen Dialekte des Burgenlandes und der angrenzenden Gebiete (= Österr. Akademie der Wissenschaften, Schriften der Balkankommission, Linguistische Abteilung, 25), Wien

Nyomárkay 1973: István Nyomárkay, Ein burgenländisch-kroatisches Evangelienbuch aus dem Jahre 1732, Studia slavica hungarica 19, 391-401

Sučić 2003: $\quad$ Ivo Sučić (glavni urednik), Gramatika gradiśćanskohrvatskoga jezika, Željezno

A b s t ra c t: László Hadrovics's occupation with the language and culture of the Burgenland Croats. The Hungarian professor and member of the Hungarian academy of Sciences, László Hadrovics, born just over a hundred years ago (1910), was undoubtedly the most prominent expert on the literary language and culture of the Burgenland Croats. This article deals with his monograph Schrifttum und Sprache der Burgenländischen Kroaten im 18. und 19. Jahrhundert (1974), which is characterized by a thorough description of the language of Croatian books and other documents of the 18th and 19th centuries. Additionally, all his minor works on the same topic are included and taken into consideration in this survey. Hadrovics's co-operation with Viennese slavists is also described.

K e y w o r d s: László Hadrovics, Croatian dialectology, literary language of the Burgenland Croats, history of the Croatian language, grammar

Gerhard Neweklowsky

Emil Mendegasse 15

9073 Klagenfurt, Österreich

gerhard.neweklowsky@uni-klu.ac.at 